\title{
Chemical Structure and Acaricidal Activity of 3-Alkylthiophenyl 4-Nitrophenyl Ethers ${ }^{\dagger}$
}

\author{
Shoichi Kato, Satoshi Inada, Shuichi Ishida, Yukio AokI \\ and Shizuo WAKITA \\ Ageo Research Laboratory, Nippon Kayaku Co., Ltd., \\ Koshikiya, Ageo, Saitama Pref., Japan
}

Received March 6, 1975

\begin{abstract}
Many 4-nitro diphenylether derivatives with $\mathrm{R}-\mathrm{S}(\mathrm{O})_{x}$-substituents were systematically synthesized and their pesticidal activities were investigated. 3-n-Propylthiophenyl 4-nitrophenyl ether and its sulfoxide analog exhibited remarkable acaricidal and chlorosis-inducing activities on the young leaves of plants. For all compounds with the substituent at the 4 position in the 3-n-propylthio (and -sulfinyl) phenyl group, chlorosis-inducing activity vanished and an acaricidal activity stronger than that of the parent compound appeared. Evidence that the acaricidal and chlorosis-inducing activities are greatly influenced by the size of the 4-substituent and the hydrophobicity of $\mathrm{R}$ in the 3-R-S (O) $)_{x}$-substituent is presented.
\end{abstract}

A number of derivatives of 4-nitro diphenylether are known to possess herbicidal activity. NIP (2, 4-dichlorophenyl 4-nitrophenyl ether), CNP (2, 4, 6-trichlorophenyl 4-nitrophenyl ether), and Chlomethoxynil (2, 4-dichlorophenyl 3-methoxy-4-nitrophenyl ether) are the widely used herbicides in our country. We systematically synthesized many 4-nitro diphenylether derivatives bearing alkylthio, alkylsulfinyl, or alkylsulfonyl radicals and investigated both herbicidal and acaricidal activities of these compounds.

Table I shows that the acaricidal activities are remarkable in the $m$ - and $p$-alkylthio and alkylsulfinyl derivatives, but not in the $o$ isomers nor in any of the alkylsulfonyl derivatives. Of these compounds, 3-n-propylthiophenyl 4-nitrophenyl ether and its sulfoxide analog $(x=1)$ were the most active. However, they induced severe chlorosis on the young leaves of plants. Thus, new derivatives which possess high acaricidal activity, but do not produce chlorosis were investigated. We found that 3-n-propylthiophenyl 4-nitrophenyl ethers with an appropriate substituent at the

+ This paper was presented at the Annual Meeting of the Agricultural Chemical Society of Japan in Tokyo, April, 1974.
4 position of the 3-n-propylthiophenyl group $(\mathrm{x}=0)$ and their sulfoxide analogs $(\mathrm{x}=1)$ did not induce chlorosis and showed even higher activity than the parent compound against Tetranychus urticae and Panonychus citri.

\section{MATERIALS AND METHODS}

\section{Synthesis}

Four typical preparations are given below. Results are shown in Table II.

Method A. 4-Chloro-3-n-propylthiophenyl 4-nitrophenyl ether (9). 4-Chloro-3-(n-propylthio) phenol ${ }^{11}$ $(5.0 \mathrm{~g}, 0.0247 \mathrm{~mole})$ and $85.5 \%$ potassium hydroxide $(1.7 \mathrm{~g}, 0.0258 \mathrm{~mole})$ were dissolved in $\mathrm{N}, \mathrm{N}$-dimethylacetamide $(50 \mathrm{ml})$ above $90^{\circ} \mathrm{C}$. 4-Chloronitrobenzene $(3.9 \mathrm{~g}, 0.0247 \mathrm{~mole})$ was added to this solution below $90^{\circ} \mathrm{C}$ and the mixture was stirred at $140 \sim 150^{\circ} \mathrm{C}$ for $3 \mathrm{hr}$. After cooling, the reaction mixture was poured into water $(200 \mathrm{ml})$ and extracted twice with benzene. The combined organic layers were washed with $5 \%$ sodium hydroxide solution, $5 \%$ hydrochloric acid solution, and water, then dried over sodium sulfate. Evaporation of the solvent left a crystalline residue, which was recrystallized from ethyl alcohol to give $7.4 \mathrm{~g}(88.2 \%)$ of 9 , pale yellow crystals, $\mathrm{mp} 90 \sim 91^{\circ} \mathrm{C}$.

Method B. 4-Chloro-3-n-propylsulfinylphenyl 4nitrophenyl ether $(10)$. Thirty percent hydrogen peroxide solution $\left(2.5 \mathrm{~g}, 0.0257\right.$ mole) was added at $8 \sim 10^{\circ} \mathrm{C}$ to a mixture of 4-chloro-3-n-propylthiophenyl 4-nitro- 
Table I. Results ${ }^{a /}$ from Screening TeSt of

$\mathrm{R}(\mathrm{O})_{\mathrm{S}} \mathrm{O}-0<-\mathrm{NO}_{2}$

ON Tetranychus urticae AND Panonichus citri

\begin{tabular}{|c|c|c|c|c|c|c|c|c|c|c|c|c|c|}
\hline \multirow{4}{*}{ Isomer } & \multirow{4}{*}{$\mathbf{R}$} & \multicolumn{12}{|c|}{$\mathrm{x}$} \\
\hline & & \multicolumn{4}{|c|}{0} & \multicolumn{4}{|c|}{1} & \multicolumn{4}{|c|}{2} \\
\hline & & \multicolumn{2}{|c|}{ T.u. ${ }^{b 1}$} & \multicolumn{2}{|c|}{ P.c. ${ }^{e)}$} & \multicolumn{2}{|c|}{ T.u. } & \multicolumn{2}{|c|}{ P.c. } & \multicolumn{2}{|c|}{ T.u. } & \multicolumn{2}{|c|}{ P c. } \\
\hline & & $\mathrm{a}^{d \prime}$ & $e^{e t}$ & $\mathrm{a}$ & $\mathrm{e}$ & a & $\mathrm{e}$ & $\mathrm{a}$ & e & a & e & a & e \\
\hline \multirow{9}{*}{$\begin{array}{l}\text { meta } \\
\text { (I) }\end{array}$} & $\mathrm{CH}_{3}$ & $\mathrm{C}$ & $\mathrm{D}$ & D & $\mathrm{D}$ & & & & & $\mathrm{C}$ & D & D & $\mathrm{C}$ \\
\hline & $\mathrm{C}_{2} \mathrm{H}_{5}$ & & & B & B & $\mathrm{D}$ & $\mathrm{D}$ & D & D & C & D & D & $\mathrm{C}$ \\
\hline & $n \cdot \mathrm{C}_{3} \mathrm{H}_{7}$ & $\mathrm{C}$ & A & C & B & C & B & A & A & C & D & $\mathrm{C}$ & C \\
\hline & iso $\cdot \mathrm{C}_{3} \mathrm{H}_{7}$ & B & $\mathrm{C}$ & C & D & $\mathrm{C}$ & D & D & C & $\mathrm{C}$ & D & D & D \\
\hline & $n \cdot \mathrm{C}_{4} \mathrm{H}_{9}$ & C & $\mathrm{C}$ & A & A & D & D & $\mathrm{C}$ & D & D & D & & \\
\hline & $n \cdot \mathrm{C}_{5} \mathrm{H}_{11}$ & C & $\mathrm{C}$ & C & C & C & D & D & C & C & D & D & C \\
\hline & $n \cdot \mathrm{C}_{6} \mathrm{H}_{13}$ & $\mathrm{C}$ & $\mathrm{D}$ & A & $\mathrm{C}$ & C & $\mathrm{D}$ & A & C & D & D & D & D \\
\hline & $\mathrm{CH}_{2}=\mathrm{CH} \cdot \mathrm{CH}_{2}$ & D & D & $\mathrm{C}$ & D & D & $\mathrm{D}$ & $\mathrm{C}$ & $\mathrm{C}$ & D & D & D & D \\
\hline & $\mathrm{CH} \equiv \mathrm{C} \cdot \mathrm{CH}_{2}$ & $\mathrm{D}$ & $\mathrm{C}$ & $\mathrm{C}$ & B & D & D & & & $\mathrm{D}$ & D & $\mathrm{C}$ & D \\
\hline \multirow{5}{*}{$\begin{array}{l}\text { para } \\
\text { (II) }\end{array}$} & $\mathrm{CH}_{3}$ & & & $\mathrm{C}$ & $\mathrm{C}$ & $\mathrm{C}$ & D & D & C & & & D & $\mathrm{C}$ \\
\hline & $\mathrm{C}_{2} \mathrm{H}_{5}$ & $\mathrm{~B}$ & $\mathrm{C}$ & A & B & C & D & $\mathrm{C}$ & $\mathrm{C}$ & D & D & $\mathrm{C}$ & C \\
\hline & $n \cdot \mathrm{C}_{3} \mathrm{H}_{7}$ & $\mathrm{C}$ & $\mathrm{D}$ & C & A & D & $\mathrm{D}$ & D & B & $\mathrm{D}$ & D & C & C \\
\hline & $n \cdot \mathrm{C}_{4} \mathrm{H}_{9}$ & $\mathrm{C}$ & D & A & C & $\mathrm{C}$ & D & $\mathrm{C}$ & A & D & $\mathrm{D}$ & C & $\mathrm{C}$ \\
\hline & $\mathrm{CH}_{2}=\mathrm{CH} \cdot \mathrm{CH}_{2}$ & $\mathrm{C}$ & $\mathrm{D}$ & A & $\mathrm{C}$ & $\mathrm{C}$ & D & D & D & $\mathrm{C}$ & $\mathrm{D}$ & D & D \\
\hline \multirow{2}{*}{$\begin{array}{l}\text { ortho } \\
\text { (III) }\end{array}$} & $\mathrm{CH}_{3}$ & D & $\mathrm{D}$ & $\mathrm{C}$ & D & & & & & $\mathrm{D}$ & $\mathrm{D}$ & $\mathrm{C}$ & C \\
\hline & $n \cdot \mathrm{C}_{3} \mathrm{H}_{7}$ & D & $\mathrm{D}$ & $\mathrm{C}$ & D & D & $\mathrm{D}$ & $\mathrm{C}$ & $\mathrm{C}$ & D & D & $\mathrm{C}$ & $\mathrm{C}$ \\
\hline
\end{tabular}

a) Activities are classified as $\mathrm{A}, \mathrm{B}, \mathrm{C}$ and $\mathrm{D}$ : $\mathrm{A}=$ the most active and $\mathrm{D}=$ inactive. $\mathrm{A}$ test compound was prepared as a $20 \%$ emulsifiable solution and was diluted with water to $400 \mathrm{ppm}$. The leafdipping method was used for these tests.

b) Tetranychus urticae. o) Panonichus citri. d) Adults. e) Eggs.

phenyl ether (9) (3.2 g, 0.0094 mole) and glacial acetic acid $(50 \mathrm{ml})$. After $5 \mathrm{hr}$ at room temperature, the reaction mixture was poured into water $(100 \mathrm{ml})$ and extracted three times with benzene. The combined organic layers were washed with $5 \%$ sodium carbonate solution, then with water and dried over sodium sulfate. Evaporation of the solvent left a crystalline residue. Recrystallization from ethyl alcohol gave $3.1 \mathrm{~g}(95.9 \%)$ of 10 , pale yellow crystals, $\mathrm{mp} 86 \sim 86.5^{\circ} \mathrm{C}$.

Method C. 4-Chloro-3-n-propylsulfonylphenyl 4nitrophenyl ether (1I). 4-Chloro-3-n-propylthiophenyl 4-nitrophenyl ether (9) (4.0 g, 0.0118 mole) was dissolved in glacial acetic acid $(40 \mathrm{ml})$, to which $30 \%$ hydrogen peroxide solution $(4.0 \mathrm{~g}, 0.0353$ mole) was added at $8 \sim 10^{\circ} \mathrm{C}$. The mixture was heated at $90^{\circ} \mathrm{C}$ for $3 \mathrm{hr}$, then cooled, and poured into water $(100 \mathrm{ml})$. The precipitates were filtered and recrystallization from ethyl alcohol gave $4.1 \mathrm{~g}(93.5 \%)$ of 11 , pale yellow crystals, mp $61 \sim 61.5^{\circ} \mathrm{C}$.

Method D. 4-Nitro-3-n-propylthiophenyl 4-nitrophenyl ether (14)

Preparation of 5-chloro-2-nitrophenyl n-propyl sulfide.
$n$-Propylmercaptan (50 g, 0.657 mole) in dioxane $(100 \mathrm{ml})$ was added to a solution of 2,4-dichloronitrobenzene (132.2 $\mathrm{g}, 0.689 \mathrm{~mole})$ and potassium carbonate $(90.7 \mathrm{~g}, 0.657 \mathrm{~mole})$ in dioxane $(100 \mathrm{ml})$ and $\mathrm{N}, \mathrm{N}$ dimethylacetamide $(60 \mathrm{ml})$ below $50^{\circ} \mathrm{C}$. The mixture was heated for $12 \mathrm{hr}$ at $80^{\circ} \mathrm{C}$, then cooled, poured into water ( 2 liters), and extracted twice with benzene. The combined organic layers were washed with $10 \%$ sodium hydroxide solution, $5 \%$ hydrochloric acid solution, and water, then dried over sodium sulfate. Evaporation of the solvent left a crystalline residue. Recrystallization from methyl alcohol gave $115 \mathrm{~g}$ $(75.6 \%)$ of yellow crystals, mp $74.5 \sim 5^{\circ} \mathrm{C}$. Anal. Found: $\mathrm{C}, 46.66 ; \mathrm{H}, 4.23 ; \mathrm{N}, 6.17$. Calcd. for $\mathrm{C}_{9} \mathrm{H}_{10} \mathrm{ClNO}_{2} \mathrm{~S}: \mathrm{C}, 46.66 ; \mathrm{H}, 4.35 ; \mathrm{N}, 6.04 \%$. ((This product was identified as 5-chloro-2-nitrophenyl npropyl sulfide, not as 3-chloro-4-nitrophenyl $n$-propyl sulfide, using the following sequence. By the reaction with sodium methoxide, this compound (5-chloro-2nitrophenyl $n$-propyl sulfide) gave the methoxy derivative (5-methoxy-2-nitrophenyl $n$-propyl sulfide), which was reduced to the amino derivative (2-amino-5methoxyphenyl $n$-propyl sulfide). Applying the Sand- 


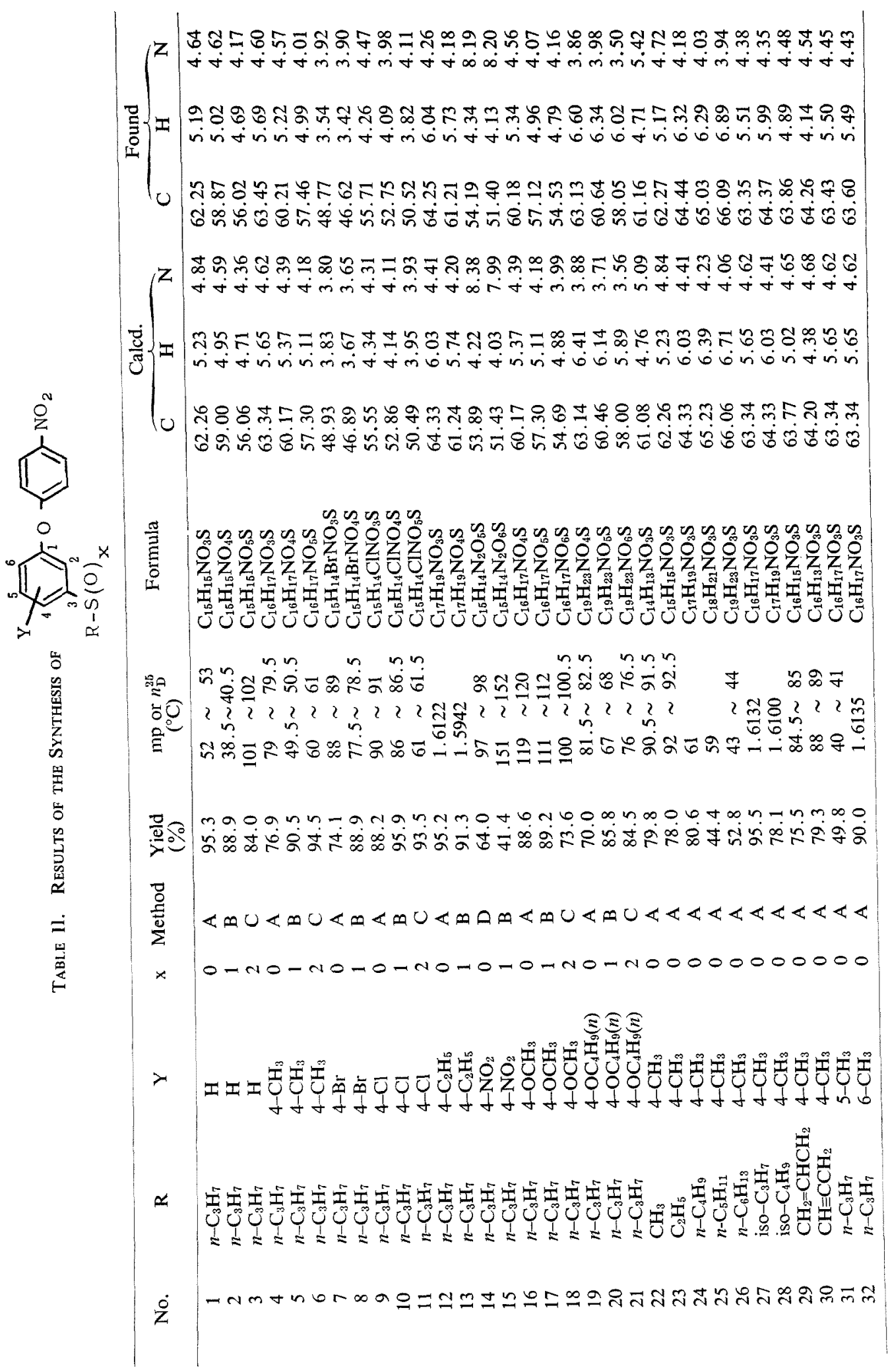


meyer reaction, the latter was finally converted to the chloro derivative (2-chloro-5-methoxyphenyl $n$-propyl sulfide), whose physical properties were identical with an authentic sample prepared from methyl iodide and 2-chloro-5-hydroxyphenyl $n$-propyl sulfide. $\left.{ }^{1 \prime}\right)$ )

Preparation of 4-nitro-3-n-propylthiophenyl 4-nitrophenyl ether (14). A mixture of 5-chloro-2-nitrophenyl $n$-propyl sulfide ( $10 \mathrm{~g}, 0.043 \mathrm{~mole})$, 4-nitrophenol $(6.0 \mathrm{~g}, 0.043 \mathrm{~mole})$, potassium carbonate $(7.2 \mathrm{~g}, 0.052$ mole) and $\mathrm{N}, \mathrm{N}$-dimethylacetamide $(40 \mathrm{ml})$ was refluxed for $5 \mathrm{hr}$. After cooling, the reaction mixture was poured into water $(200 \mathrm{ml})$ and extracted twice with benzene. The combined organic layers were sequentially washed with $5 \%$ sodium hydroxide solution, $5 \%$ hydrochloric acid solution, and water, then dried over potassium sulfate. Evaporation of the solvent left a crystalline residue. Recrystallization from methyl alcohol gave $9.2 \mathrm{~g}(64.0 \%)$ of 14 , yellow crystals, mp $97 \sim 98^{\circ} \mathrm{C}$.

\section{Biological tests}

Every active ingredient of chemical grade was used for the biological test as a $20 \%$ emulsifiable solution prepared by mixing the active ingredient, xylene, isopropylalcohol and polyoxyethylenealkylphenol in a ratio of $20: 20: 35: 25$.

1) Determination of acaricidal activity against Tetranychus urticae. Fifteen female adults of Tetranychus urticae were infested on the first leaves (two leaves), cut into squares $(2 \mathrm{~cm} \times 2 \mathrm{~cm})$, of dwarf Phaseolus vulgaris grown in a porous pot. After one day, the leaves were dipped into the test solution diluted to a concentration of $0.04 \%$ with water. These insects were then raised in a greenhouse at $25^{\circ} \mathrm{C}$.
Dead adults were counted through a binocular microscope two days after treatment. The survivors were removed and the deposited eggs were counted. Unhatched eggs were counted one week later.

2) Determination of acaricidal activity against Panonychus citri. Pairs of leaves of dwarf Citrus natsudaidai seedlings grown in a porous pot were excised. "Tangle-foot" (pine resin) was applied to the petiole of the two leaves. Fifteen female adults of Panonychus citri per one leaf were infested. After one day, a test solution diluted to $0.04 \%$ with water was sprayed on the leaves for $20 \mathrm{sec}$ in a pot placed on a turn-table $(16 \mathrm{rpm})$ using a compressor-spray-gun $\left(1.5 \mathrm{~kg} / \mathrm{cm}^{2}\right)$. The pot was then placed in a greenhouse at $25^{\circ} \mathrm{C}$. The mortalities of adults and eggs were measured as described above.

3) Determination of $L C_{50}$ against Tetranychus urticae Cotyledons of dwarf Phaseolus vulgaris were cut into squares $(2 \mathrm{~cm} \times 2 \mathrm{~cm})$ and placed on an agar gel in a petri dish with their backs upwards. Twenty female adults of Tetranychus urticae were placed on the cotyledons. After one day, dead and unhealthy mites were removed and $7 \mathrm{ml}$ of a test solution diluted to a given concentration was sprayed on the squares with a turning spray tower of the "Mizuho-style" (280 mmHg). Two days after treatment, mortality was measured through a binocular microscope and the $\mathrm{LC}_{50}$ was calculated using Bliss' probit method.

\section{RESULTS}

1. 4-Substituted-3-n-propylthiophenyl 4-nitrophenyl ethers, sulfoxide and sulfone deriva-

TABLE III. ResUlts ${ }^{a}$ ) FROM SCREening TeSt OF

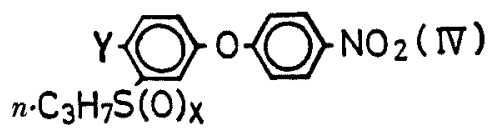

ON Tetranychus urticae AND Panonychus citri

\begin{tabular}{|c|c|c|c|c|c|c|c|c|c|c|c|c|}
\hline \multirow{4}{*}{$\mathrm{Y}$} & \multicolumn{12}{|c|}{$x$} \\
\hline & \multicolumn{4}{|c|}{0} & \multicolumn{4}{|c|}{1} & \multicolumn{4}{|c|}{2} \\
\hline & \multicolumn{2}{|c|}{ T.u. } & \multicolumn{2}{|c|}{ P.c. } & \multicolumn{2}{|c|}{ T.u. } & \multicolumn{2}{|c|}{ P.c. } & \multicolumn{2}{|c|}{ T.u. } & \multicolumn{2}{|c|}{ P.c. } \\
\hline & a & e & a & e & $\mathrm{a}$ & $\mathrm{e}$ & $\mathrm{a}$ & $\mathrm{e}$ & $\mathrm{a}$ & $\mathrm{e}$ & $\mathbf{a}$ & e \\
\hline $\mathrm{CH}_{3}$ & $A$ & $\mathrm{~A}$ & $\mathrm{~A}$ & $\mathrm{~A}$ & $\mathrm{~A}$ & A & A & A & $\mathrm{C}$ & $\mathrm{D}$ & D & D \\
\hline $\mathrm{C}_{2} \mathrm{H}_{5}$ & A & A & A & A & A & A & A & A & & & & \\
\hline $\mathrm{Br}$ & $\mathrm{A}$ & $\mathrm{A}$ & $\mathrm{D}$ & $\mathrm{C}$ & A & $\mathrm{A}$ & A & A & & & & \\
\hline $\mathrm{Cl}$ & A & A & $\mathrm{D}$ & $\mathrm{C}$ & A & A & A & A & D & D & $\mathrm{C}$ & $\mathrm{C}$ \\
\hline $\mathrm{H}$ & $\mathrm{C}$ & $\mathrm{A}$ & $\mathrm{C}$ & B & C & B & A & A & $\mathrm{C}$ & $\mathrm{D}$ & C & C \\
\hline $\mathrm{NO}_{2}$ & $\mathrm{D}$ & $\mathrm{D}$ & D & D & D & $\mathrm{C}$ & $\mathrm{D}$ & $\mathrm{D}$ & & & & \\
\hline $\mathrm{OCH}_{3}$ & $\mathrm{C}$ & $\mathrm{C}$ & D & D & $\mathrm{C}$ & $\mathrm{C}$ & A & $\mathrm{C}$ & $\mathrm{C}$ & $\mathrm{C}$ & D & D \\
\hline $\mathrm{OC}_{4} \mathrm{H}_{9}(n)$ & $\mathrm{D}$ & $\mathrm{D}$ & D & $\mathrm{C}$ & $\mathrm{D}$ & $\mathrm{D}$ & $\mathrm{C}$ & D & D & D & $\mathrm{D}$ & C \\
\hline
\end{tabular}

a) See notes under Table I. 
tives (IV)

As shown in Table III, most of the sulfide $(x=0)$ and the sulfoxide $(x=1)$ derivatives exhibited remarkable acaricidal activities, but all the sulfone $(x=2)$ derivatives showed low activities. Activities of the sulfides against $T$. urticae were A class against both adults and eggs when $\mathrm{Y}=$ methyl, ethyl, bromine or chlorine. The activity of the parent compound ( $\mathrm{Y}=$ hydrogen) was $\mathrm{A}$ class only against eggs and was $C$ class against adults. Other compounds ( $\mathrm{Y}=$ methoxy, nitro or $n$-butoxy) showed low activities. The activities of the sulfides, where $\mathrm{Y}=$ methyl or ethyl against $P$. citri were evaluated as A class. The parent compound $(\mathrm{Y}=$ hydrogen $)$ showed $\mathrm{B}$ class activity only against eggs, as against $T$. urticae. Thus, the selective action of the sulfides against the two species depends on substituent $Y$. The activities of the sulfoxides against $T$. urticae were quite similar to those of the sulfides. But sulfoxides with hydrogen, methyl, ethyl, chlorine or bromine as $\mathrm{Y}$ were highly active against both the adults and eggs of $P$. citri. The sulfoxide with methoxy as $\mathrm{Y}$ was

TABle IV. Miticidal Activity ${ }^{a}$ of

$$
{ }_{n \cdot \mathrm{C}_{3} \mathrm{H}_{7} \mathrm{~S}(\mathrm{O})_{X}} \bigcirc-\mathrm{NO}_{2}(\mathrm{IV})
$$

\begin{tabular}{|c|c|c|c|c|}
\hline \multirow{3}{*}{$\mathrm{Y}$} & \multirow{3}{*}{$\mathbf{r}_{\mathrm{v}}^{b)}$} & \multirow{3}{*}{$\sigma^{c)}$} & \multicolumn{2}{|c|}{$x$} \\
\hline & & & 0 & 1 \\
\hline & & & $\mathrm{LC}_{50}$ & $\mathbf{L C}_{50}$ \\
\hline $\mathrm{CH}_{3}$ & 1.97 & -0.170 & $7 \mathrm{ppm}$ & $6 \mathrm{ppm}$ \\
\hline $\mathrm{Br}$ & 1.85 & 0.232 & 11 & 6 \\
\hline $\mathrm{Cl}$ & 1.75 & 0.227 & 13 & 11 \\
\hline $\mathrm{C}_{2} \mathrm{H}_{5}$ & & -0.151 & 45 & 16 \\
\hline $\mathbf{H}$ & 1.20 & 0.000 & 130 & 188 \\
\hline $\mathrm{NO}_{2}$ & 2.59 & 0.778 & \multirow{3}{*}{\multicolumn{2}{|c|}{$\begin{array}{l}0 \% \text { mortality } \\
\text { at } 200 \mathrm{ppm}\end{array}$}} \\
\hline $\mathrm{OCH}_{3}$ & & -0.268 & & \\
\hline $\mathrm{OC}_{4} \mathrm{H}_{9}(n)$ & & & & \\
\hline
\end{tabular}

AGAINST Female Tetranychus urticae

a) The test compound was prepared as a $20 \%$ emulsifiable solution and was diluted with water to serial concentrations.

The leaf-disk method was used for these tests. $\mathrm{LC}_{50}$ was calculated by Bliss' probit method.

b) Van der Waals radii. ${ }^{31}$

c) Hammett's substituent constants. ${ }^{4}$ active only against the adults. The sulfoxides have a great selective toxicity against $P$. citri when compared with the toxicity of the sulfides. Since the activities of the sulfides and sulfoxides against the adults of $T$. urticae seemed to depend on the substituent $Y$, a structure-activity correlation was quantatively studied. The compounds investigated and their miticidal activities $\left(\mathrm{LC}_{50}\right)$ are shown in Table IV. The Hansch approach ${ }^{2}$ gave no clear correlation between $-\log \mathrm{LC}_{50}$ and $\sigma, \pi$ or the combination of $\sigma$ and $\pi$ of the substituent Y. However, as
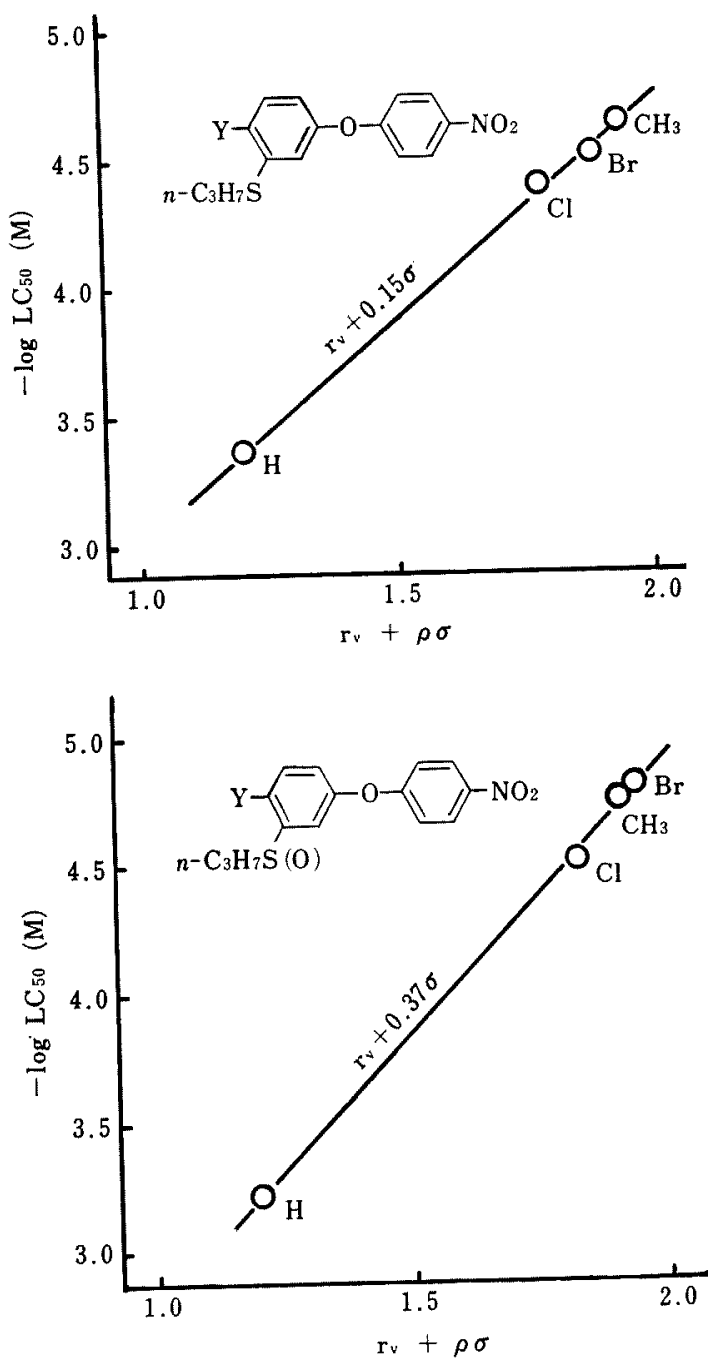

FIg. 1. Correlation between Miticidal Activity $\left(-\log \mathrm{LC}_{50}\right)$ v.s. Female Tetranychus urticae and the Physicochemical Parameters, $r_{v}$ and $\sigma$. 
shown in Fig. 1, a high correlation was found between $-\log \mathrm{LC}_{50}$ and the combination of van der Waals radii $\left(\mathrm{r}_{\nabla}\right)$ and $\sigma$. This correlation indicates that the activity is greatly influenced by the size of substituent $Y$. The activity of the sulfide is more dependent on size than is that of sulfoxide. When the methyl radical was moved from the 4- position to the 3- or 2position, activity decreased drastically (Table V). This large depression in activity cannot be explained by the term $\sigma$ or $\pi$. Therefore the substituent $\mathrm{Y}$ at the 4-position is thought to

Table V. Miticidal Activity ${ }^{a}$ of

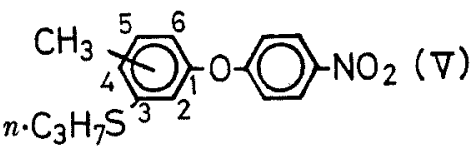

AGAINST Female Tetranychus urticae

\begin{tabular}{ccc}
\hline Position & \multicolumn{2}{c}{ Mortality $(\%)$} \\
& $100 \mathrm{ppm}$ & $200 \mathrm{ppm}$ \\
\hline $6 \cdot \mathrm{CH}_{3}$ & 0 & 0 \\
$5 \cdot \mathrm{CH}_{3}$ & 11 & 11 \\
$4 \cdot \mathrm{CH}_{3}$ & 100 & 100 \\
\hline Control & 0 & 0 \\
\hline a) See note & S) & \\
\hline
\end{tabular}

TABle VI. Miticidal Activity ${ }^{a /}$ of

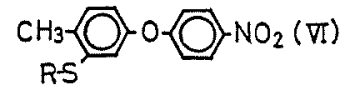

against Female Tetranychus urticae

\begin{tabular}{clrrr}
\hline $\mathrm{R}$ & $\pi^{b)}$ & \multicolumn{3}{c}{ Mortality $(\%)$} \\
& & 50 ppm & 100ppm & 200ppm \\
\hline $\mathrm{CH}_{3}$ & 0.50 & & 8 & 12 \\
$\mathrm{CH} \equiv \mathrm{C} \cdot \mathrm{CH}_{2}$ & $0.90^{\circ}$ & 37 & 89 & 97 \\
$\mathrm{C}_{2} \mathrm{H}_{5}$ & 1.00 & 92 & 98 & 100 \\
$\mathrm{CH}_{2}=\mathrm{CH} \cdot \mathrm{CH}_{2}$ & $\left.1.20^{c}\right)$ & 92 & 100 & 100 \\
iso $\cdot \mathrm{C}_{3} \mathrm{H}_{7}$ & 1.30 & 90 & 97 & 100 \\
$n \cdot \mathrm{C}_{3} \mathrm{H}_{7}$ & 1.50 & 100 & 100 & 100 \\
iso $\cdot \mathrm{C}_{4} \mathrm{H}_{9}$ & 1.80 & 73 & 98 & 100 \\
$n \cdot \mathrm{C}_{4} \mathrm{H}_{9}$ & 2.00 & & 53 & 89 \\
$n \cdot \mathrm{C}_{5} \mathrm{H}_{11}$ & 2.50 & & 8 & 24 \\
$n \cdot \mathrm{C}_{6} \mathrm{H}_{13}$ & 3.00 & & 18 & 31 \\
\hline Control & & & 0 & 0
\end{tabular}

a) See note ${ }^{a}$ ) Table IV.

b) Hansch's hydrophobic substituent constants. ${ }^{51}$

c) $\pi$ values were estimated using their additive nature. ${ }^{6,7)}$ fit on a site of limited size. This specified site, if any, should be very small in the system of chlorophyll synthesis, because only the parent compound induced chlorosis.

\section{3-(R-S)-4-Methylphenyl 4-nitrophenyl ethers}

(VI)

4-Methylphenyl 4-nitrophenyl ether derivatives with the alkylthio, allylthio, or propinylthio radical substituted at the 3-position were studied to clarify the effect of the aliphatic group binding to sulfur on acaricidal activity. Results in Table VI indicate that the activity is closely related to the hydrophobic parameter $(\pi)$ of the aliphatic group, R.

\section{DISCUSSION}

The above study of structure-activity-relationships strongly suggests that the mode of action against adult mites by 4-(Y)-3-(alkylthio) phenyl 4-nitrophenyl ethers and their sulfoxides involves fitting of the 4-substituent $Y$ on a specified site and the hydrophobic binding of the alkyl radical on a lipoproteinic site. The same explanation can be given for the action against eggs. Differences in susceptibility against the same chemical toxicant have often been observed between $T$. urticae and $P$. citri. $^{8 \sim 10)}$ Therefore, it is not strange that the sulfoxides show distinctly higher activity against $P$. citri than against $T$. urticae. The sulfides and sulfoxides exhibited exactly the same order of activity against $T$. urticae. Sulfides and sulfoxides and/or sulfones are known to show the relationship of substratemetabolites. The insecticidal activity of the $p$ methylthiophenyl phosphates is almost as high as the activities of the corresponding methylsulfinyl and methylsulfonyl analogs. ${ }^{11)}$ This indicates that the methylthio radical is smoothly metabolized to active methylsulfinyl and/or methylsulfonyl radicals in the insects. ${ }^{11}$ Nevertheless, the sulfoxides are more active than the sulfides against $P$. citri. Since thio, sulfinyl and sulfonyl radicals differ in their physicochemical properties, ${ }^{7}{ }^{7}$ differences in activities should appear among the sulfides, 
sulfoxides and sulfones, unless the change of $\mathrm{S} \rightarrow \mathrm{SO} \rightarrow \mathrm{SO}_{2}$ corresponds to an activating metabolism. The fact that the activity of the sulfides against $T$. urticae adults is equal to that of the sulfoxides is possibly due to the rapid activating metabolism of $\mathrm{S} \rightarrow \mathrm{SO}$. The activity of the sulfides against $P$. citri adults is lower than that of the sulfoxides. This weak sulfide activity against $P$. citri is possibly attributable to the slow metabolism of $\mathrm{S} \rightarrow \mathrm{SO}$. Further work is necessary to confirm the reason for the similarity or dissimilarity in activity between the sulfides and sulfoxides. The inactivity of the sulfones seems to be due to their weak hydrophobic bonding to the sites of action because of the negative $\pi$ value of the sulfonyl radical, or to a disturbance in the fixation of the molecule on the sites of action due to the considerable bulkiness of the sulfonyl radical.

Acknowledgement. We wish to thank Mr. Bunzo Sekine, Director of Ageo Research Laboratory, Nippon Kayaku Co., Ltd., for his advice and suggestions, also Messrs. Iwao Tejima and Hisafumi Kobayashi and Miss Teruyo Koyama of our laboratory for their support in parts of this work.

\section{REFERENCES}

1) Nippon Kayaku Co., Japan Kokai, 49-94641 (1974).

2) C. Hansch and T. Fujita, J. Am. Chem. Soc., 86, 1616 (1964).

3) E. Kutter and C. Hansch, J. Med. Chem., 12, 647 (1969).

4) D. H. Mcdaniel and H. C. Brown, J. Org. Chem., 23, 420 (1958).

5) "Biological Correlations-The Hansch Approach," Adv. in Chem. Series No. 114, Amer. Chem. Soc., 1972.

6) C. Hansch, Quantitative Structure-Activity Relationships in Drug Design, in "Drug Design," ed. by E. J. Ariëns, Academic Press, 1971, pp. 271 $\sim 337$.

7) M. S. Tute, Advan. Drug Res., 6, 1 (1971).

8) R. L. Metcalf, J. Econ. Entomol., 41, 875 (1948).

9) E. J. Newcomer and F. P. Dean, ibid., 42, 857 (1949)

10) G. Unterstenhoefer, Hoefchen-Briefe, 13, No. 4, 207 (1960).

11) T. Fukuto and R. Metcalf, J. Agr. Food Chem., 4, 930 (1956). 